\title{
A MANAGEMENT INFORMATION SYSTEM FOR THE SUPERVISION OF HIGHWAY CONSTRUCTION PROJECTS
}

\author{
Yueh Liang1, Ph.D., Fu-Yih Shih ${ }^{2}$, Ph.D., Chih-Hsiung Wu ${ }^{3}$ \\ Highway Bureau, Ministry of Transportation and Communications, ROC \\ 1.Director General; 2. Director of MIS Office / fuyih@thb.gov.tw; 3.Section Chief
}

\begin{abstract}
A management information system for the supervision of highway construction projects has been designed and implemented by using the Microsoft Visual FoxPro. The implemented system is so helpful that the top management officials of the Highway Bureau can fully have all the construction projects under control.
\end{abstract}

Keywords: management information system, database management

\section{INTRODUCTION}

In average, the Highway Bureau of the Ministry of Transportation and Communications handles more than hundred highway construction projects per fiscal year. Of course, the properties of the projects are different from each other. Some of them are pretty big ones, e.g. the projects of the Western Coastal Expressway, and the projects of the EastWest Expressway, while the others may only be small scale ones.

Even though finally all the construction projects are executed by the thirteen construction divisions distributed in this country, however, the projects are supervised by either one of the two engineering departments at the headquarter of the Highway Bureau. Besides that, among the hundreds of construction projects, some of them are still at the designing phase, while some other ones are ready for open tender, but the other ones may be worth for special monitoring, and so and so. Each project, of course, has its expected schedules, including the completion day of design, the open tender day, the completion day of the construction, etc.

We can imagine that it will be so difficult for the top management officials to supervise the hundreds of construction projects without an efficient management information system. The interest of the work of this paper is to design and implement a management information system for the supervision of highway construction projects.

The Microsoft Visual FoxPro [1] has been used for the implementation of this system. It is shown that the implemented system is user friendly, and is so helpful not only for the top management officials at the headquarter of the Highway Bureau but also for the directors of the construction divisions distributed in this country to monitor all the highway construction projects while they stay at their own offices, as long as the construction database is updated dynamically according to the real status of the project. To transmit the updated database of the highway construction projects from all over the country to headquarter of the Highway Bureau, the Internet facilities has been incorporated into this management information system. [2], [3]

\section{SYSTEM ANALYSIS}

In this paper, the word "projects" is used as a broad meaning. Because, in this bureau, especially for a big job, most of the times more than one projects belong to a same "plan", while a specific project may end up with many construction tenders. It means that a "plan" is the origin of the "projects", while a "project" is the origin of the "tenders".

So, for a small job, it will be nothing special that a "plan" may equivalent to a "project", and than the "project" may finally only have one "tender", and of course only have one construction contract granted. But, for a big job, a "plan" can be divided into many "projects", and each "project" can also end up with many construction "tenders".

Based on the fundamental philosophy that no matter what the construction project is, as long as it belongs to one of the highway construction projects supervised by this bureau, it should be part of the total construction database of the management information system presented in this paper. [4], [5]

\subsection{The concerned information}

For each project, the top management officials' main interests include: the relationship with the "plan" and the "tenders", the budgets, the schedules, the present status, the responsible construction division and engineering department, the consultant company and construction company, and the performances of all the concerned entities as mentioned above, etc.

The items of the budgets consist of the total budget for the entire plan, the fiscal year budget plan, the budget for land acquisition, the tender budget, 
and the contract granted value for a tender.

The most important schedules include the schedule of land acquisition, the schedule of gross design, the schedule of detail design, the schedule of approval, the schedule of open tender, the schedule of contract granted day, and the schedules of grand open day and completion day of construction work.

\subsection{Categories of the projects}

At a specific time, each project has its own status and special properties. Thus, we can categorize all the supervised construction projects into different special interest groups, such as projects still at land acquisition stage, projects still at design stage, projects ready for open tender, projects even though the construction contract already being granted but the construction work still not grand open yet, projects already completed but not accepted yet, projects that can be completed by the end of this year, projects now at pending status, and projects need special monitoring, etc.

To execute a specific project, one of the thirteen construction divisions distributed in this country will be assigned to handle it. But, at the main office of this bureau, this specific project may be controlled by either one of the two engineering departments, depending on the classification of this project. To supervise a specific project, the top management officials do need the information about the control department and, of course, the execution division. The other way, the management information system can provide the supervisors about the loadings of a specific engineering department and that of a specific construction division, such that the performances can be evaluated.

\subsection{Supervision of consultant and construction Co.}

For highway designs and constructions, there are many consultant companies and construction companies having been granted either the design or the construction contracts by this bureau. In order to supervise effectively both the consultant and the construction companies, the management information system must include their databases.

It is not unusual that one consultant or construction company may get involved with more than one highway construction project at the same time period. In order to have a qualified construction quality control, the performances of the consultant and the construction companies must be supervised.

The total number of projects, the total contract value of the awarded contracts, the deficiency records, and the fundamental backgrounds of the companies, e.g. the financial capability, the manpower, etc. are the most concerned information for the evaluation of the companies.

\subsection{Site map integration and other requirements}

To identify the route or location of a specific highway construction project, the site map will be quite helpful. Suppose we can integrate the site map into this management information system, it will make this system more powerful.

One of the main goals of implementing this management information system is to substitute the traditional paper-based reports. We expect that sooner or latter we will have a paperless meeting by using this system right in the meeting room. Based on this expectation, special technique must be applied to realize the ideals.

To update the database of this management information system at any time, all the updated data files of the thirteen construction divisions from all over the country must be transmitted to the headquarter of this bureau. It seems that the Internet system is applicable.

\section{SYSTEM DESIGN AND IMPLEMENTATION}

The system is designed to be user friendly so that the top management officials of the Highway Bureau can fully supervise all the construction projects. The Microsoft Visual FoxPro is then used to implement this management information system. [6]

\subsection{Database of highway construction projects}

In general, the database of this system consists of the tables with the interested fields as mentioned in the system analysis section. The tables are created through normalization procedure. Most of the forms of this management information system are related to the status and properties of the projects as described also in the system analysis section.

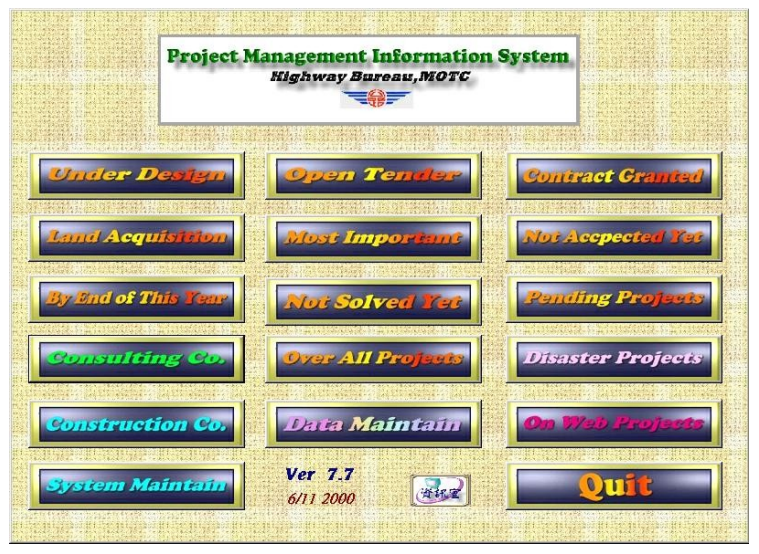

Fig.1 System Menu

The other important and interested forms include database maintenance form, system service form, and form for web bulletin board. All the forms are coordinated and can be accessed by a system menu as shown in Fig. 1.

The database maintenance form is designed mainly for the persons who maintain the system database. As long as the contents of this form is filled 
up properly, the contents of the other forms will be automatically filled up.

Referring to the data maintenance form, as shown in Fig. 2, we see that this form is composed by one title, one record number counter, and five areas including one grid area, two page-frame areas, one check box area, and one command button area.

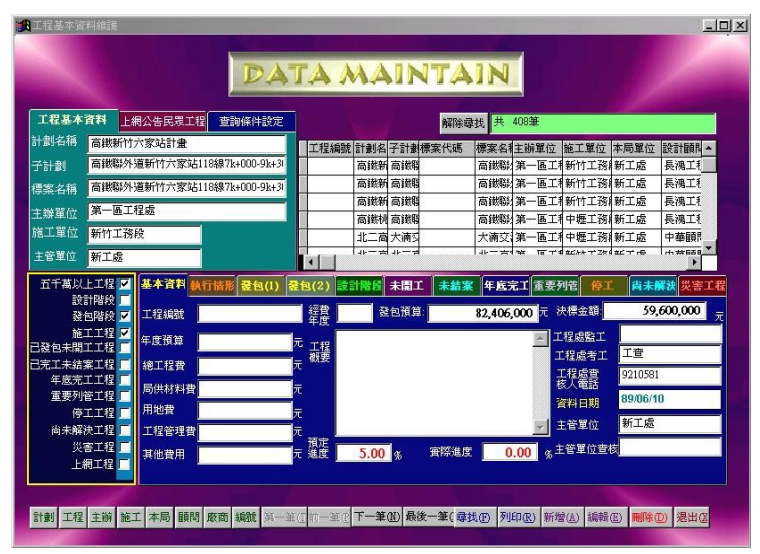

Fig.2 Database Maintenance Form

The grid area contains all records of the projects. The check box area is used to categorize the projects, depending on the status and properties of the projects as mentioned above, so that this system can automatically distribute the proper records of the projects to fill up the contents of the corresponding forms, which then can be accessed easily from the system menu.

Each project may belong to more than two categories. For example, for the time being, even though a project is still at design stage, but it may be so important that it also belongs to the project category need special monitoring. Of course, for this kind of projects, the persons, who are responsible for filling up the database maintenance form, must check the two corresponding check boxes simultaneously.

Each page of the page-frames is used for different purposes. There are totally 15 pages. Two of them are used to state the common background information of a project, e.g. plan name, project name, tender name, the responsible organizations and persons, the total budget, etc. One page is used to state the execution records of the project. For the rest of the 12 pages, one of them is reserved specially for the contents of the project to be published on the web bulletin board, another one is used for setting up the searching conditions, each one of the other 10 pages is used to state the corresponding detail information of the different categorized projects as described in the section of system analysis. The command button area consists of 18 buttons created for the purposes of sorting, searching, finding, editing, printing, and exiting.

\subsection{Forms for categorized projects}

In general, each form of the categorized projects consists mainly of a title of the form, a records number counter, a grid area, a page-frame area, a command area, and a easy setting area for searching purpose, as shown in Fig. 3.

General speaking, all the contents of a form for a specific project category are distributed from the database of the database maintenance form, and can be filled up automatically, as long as the corresponding check box having been checked properly by the database maintenance person.

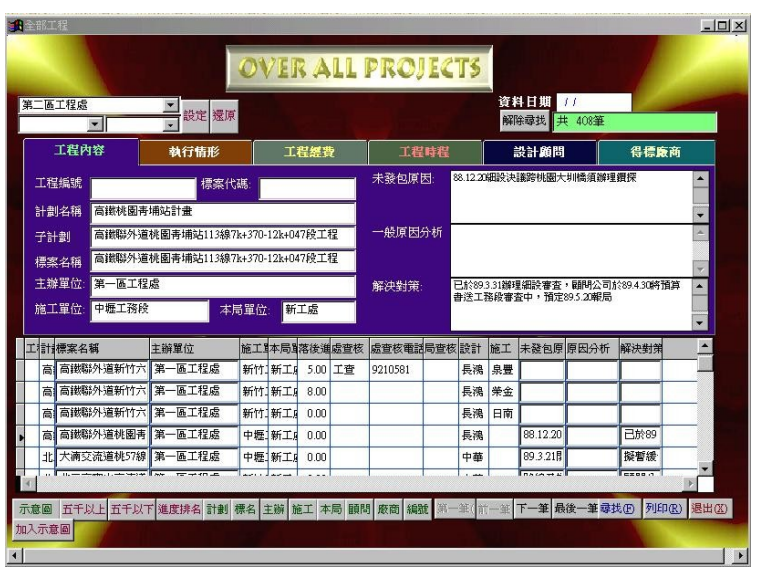

Fig.3 A Typical Form for A Categorized Project

Normally, the page-frame area of a categorized form has six pages, with first page for the project fundamental information, the second page for the execution status, the third page for the budgets, the fourth page for the schedule control, as shown in Fig.4, the fifth page for the basic information of the responsible consultant company, and the sixth page for the basic information of the contract awarded construction company.

It is a rule of thumb that the grid area of a categorized form contains always all the records of the projects belong to this specific category. It is also designed and implemented that the total number of the categorized projects can be registered in the total number counter on each corresponding form. A interested project can be accessed either by clicking the button in front of the project record in the grid area or by using the selecting buttons in the command button area. Once a project is selected from the grid area, the corresponding contents of the fields of its record will be distributed automatically to fill up the contents of the pages of the page-frame. Then the specified project can be supervised and evaluated based on the information provided by the contents of this categorized form. 


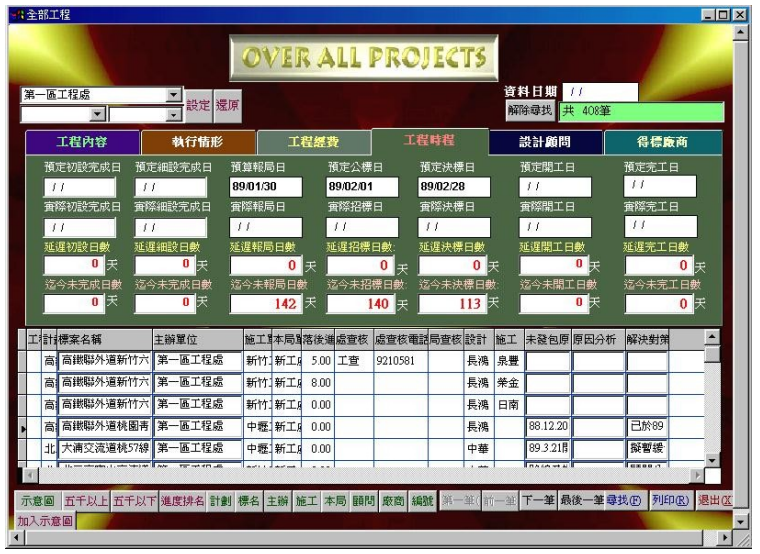

Fig.4 Page for Schedule Control

The form for the projects to be published on web bulletin board, as shown in Fig. 5, is designed to meet the public interests about the highway construction information. In this form, people can access their concerned information about the interested project, such as the responsible organizations, the constructor, the designer, the total construction budget, the construction schedule, etc.

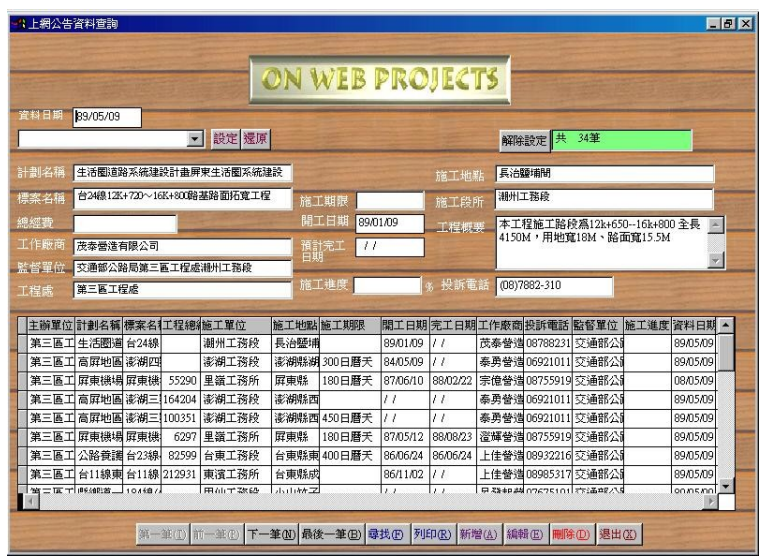

Fig.5 Form for Projects to be published on Web

In general, the Combo Box area on each one of the forms is used for the easy searching purpose, as shown on the top-left of Fig. 3 and Fig. 4. It is shown that there are three Combo Boxes, with one for the selection of the interested construction division from the listing of the 13 construction divisions of the Highway Bureau, the second one for the selection of the execution section of this interested division, and the third one for the selection of the responsible engineering department at the headquarter of the Highway Bureau. People can have different kind of searching, depending on their own purpose. All the projects having been found, under the setting of the searching conditions, then are collected in the grid area, with the first record of them being displayed in the page-frame area automatically.

\subsection{Evaluating the consultant and construction Co.}

If there are questions about the consultant company or the construction company that are related to a specific project, the supervisors can get into the forms about the consultant companies or construction companies, as shown in Fig. 6 and Fig. 7, by hitting the proper button on the system menu.

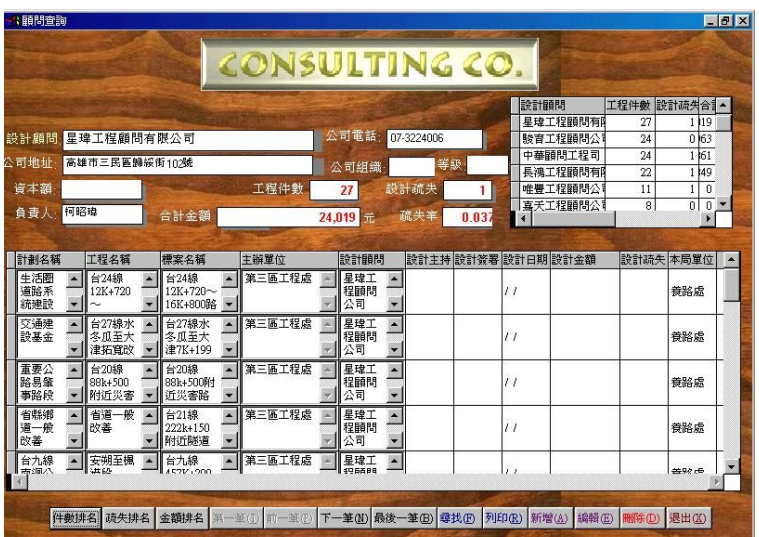

Fig.6 Evaluating the Consultant Company

The contents of the forms concerning about the consultant and construction companies include the fundamental background information of the companies, the total number and the detail listing of the highway projects each company having been got involved, the total contract value each company having been awarded, and their performance records. In the listing of the companies, we can list them by different kind of sequences, depending on the total number of granted projects, the total value of the granted contracts, or the number of bad records they ever have.

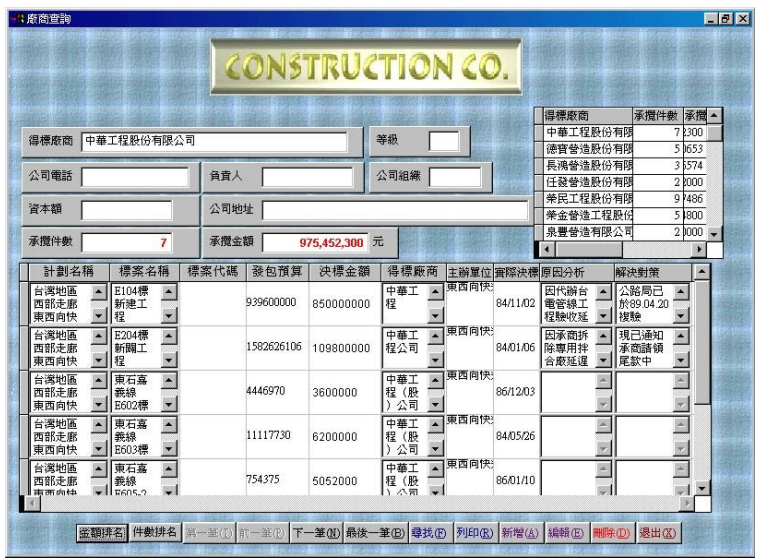

Fig.7 Evaluating the Construction Company

\subsection{Land acquisition}

The land acquisition problem is the most fundamental work of the highway construction projects. No construction project can be initiated before the land problem can be solved. To supervise the land acquisition schedule, we design a form, as shown in Fig. 8 to fulfill the requirements. 


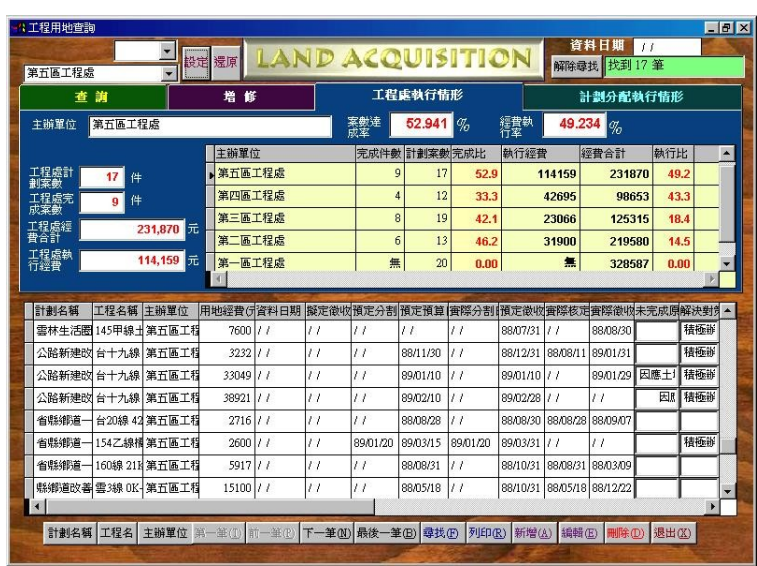

Fig.8 Land Acquisition Supervision

There are four pages in the page-frame area of the land acquisition form. Two of them are for the background information including the project name, the total project budget, the land acquisition budget, and the planned time schedules. The other two pages are for the purpose of performance evaluations including the achievement percentages of the construction divisions. The order of the names of the construction divisions can be listed according to their achievement percentages.

\subsection{Zoom technique and site map integration}

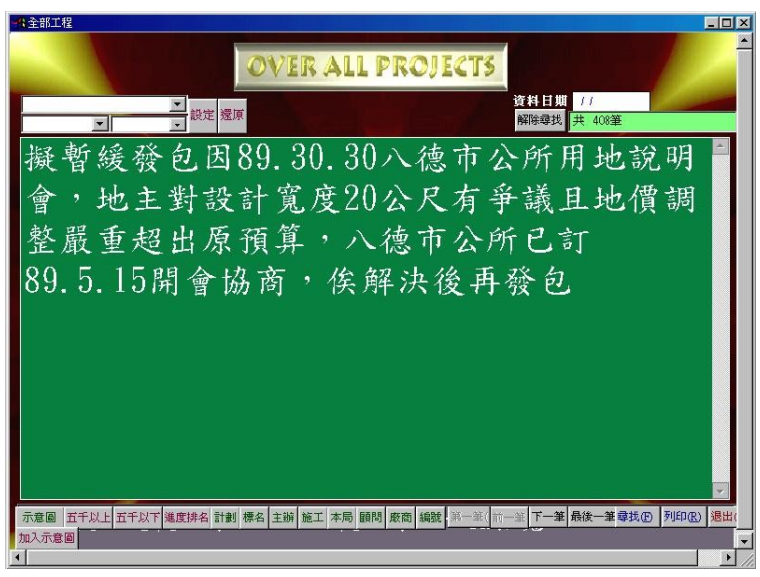

Fig.9 Zoom Technique used in the Forms

For the convenience of discussion purpose, especially during a meeting, the zoom technique has been incorporated into the design of the forms. The contents of the text editing boxes, which are for the statements of reasons and actions to be conducted, and the achievement records located in the third and fourth page of the land acquisition form can be zoomed out and recovered by simply clicking at any position of the text editing areas, as shown in Fig. 9 and Fig. 10.

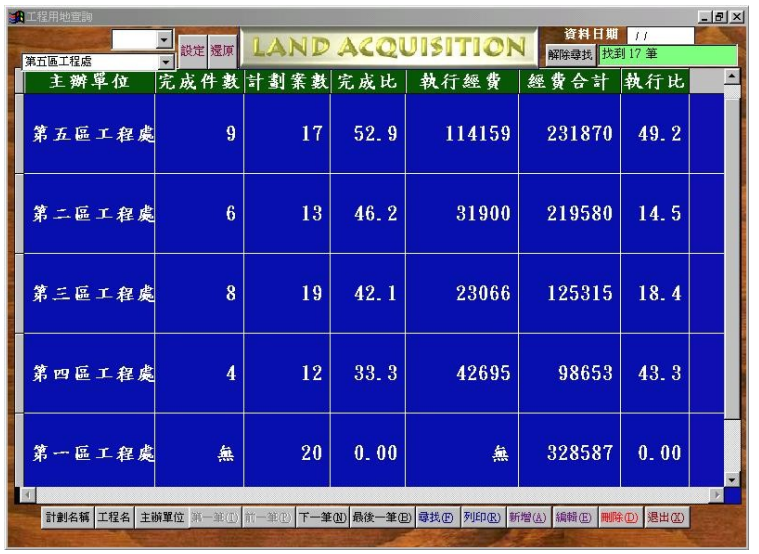

Fig.10 Zoom Technique used in the Forms

The site maps can be integrated into the database of the highway construction projects, as shown in Fig. 11. With the integration of the site maps into this management information system, it will be easier for the supervisors to identify the routes or the locations of a specific highway construction project.

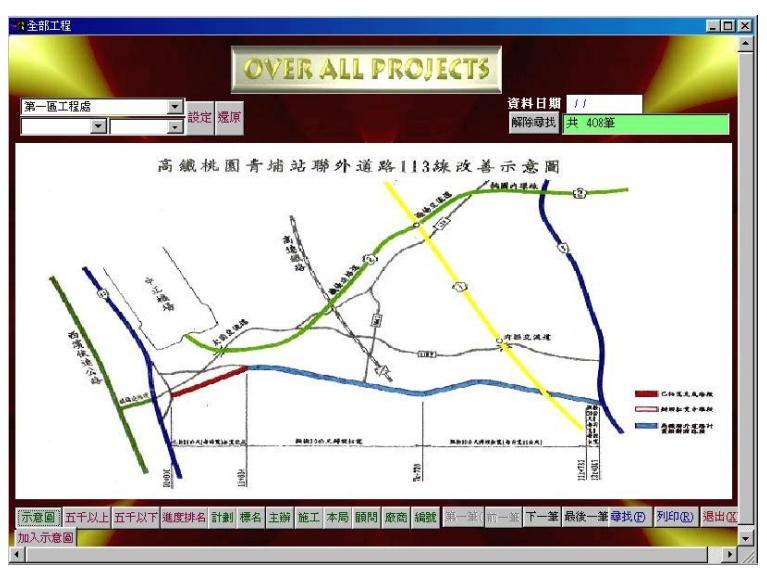

Fig.11 Site Map of a Highway Construction Project

When a specific project is studied, its corresponding site map can be accessed very easily by simply clicking the site-map button located at the left-end of the forms. If the site map is no longer necessary, we can click at any point in the area of the map to resume the original form right away.

\subsection{Transmission of data files}

To update the database of this management information system at any time, the updated data files must be transmitted to headquarter of Highway Bureau from the thirteen construction divisions distributed all over the country.

A system maintenance form has been designed to fulfill the requirements of file update and transmission, as shown in Fig.12. The system maintenance form is designed mainly to offer the following functions: (1) database update (2) database backup (3) database integration (4) transmission of database. 


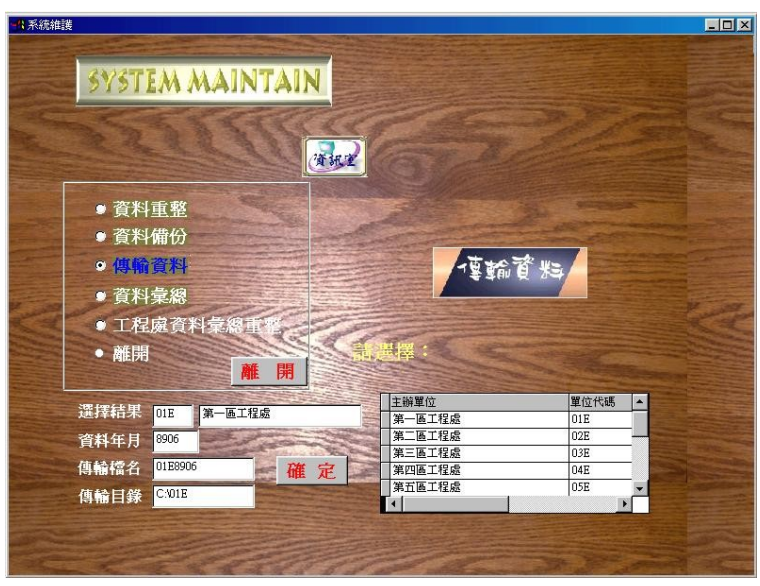

Fig.12 Form for System Maintenance

The system maintenance form consists of function selection area, construction division selection area, and area for the display of date, file name, and catalog name. Right after the completion of database update, what the database maintenance person has to do, before the "send" button is clicked, is to select his/her own construction division name from the division selection area.

This management information system then will display the date, and the chosen division name for double check. Simultaneously, the file name and the catalog name required for data transmission will be automatically generated and displayed in the display area.

Suppose nothing wrong with the displayed contents, then the "send" command button is ready to be clicked. Once the "send" button is clicked, the updated data file then will go through Internet system to the management information system at the Highway Bureau headquarter for database integration. [7], [8]

\section{CONCLUSIONS}

A management information system for the supervision of highway construction projects has been designed and implemented by using the Microsoft Visual FoxPro.

By integrating the zoom technique and the site maps of the highway construction projects into this management system, it shows that this implemented system is so practical and helpful not only for the top management officials at the headquarter of Highway Bureau to supervise all the highway construction projects, but also for the directors of the construction divisions allocated around this country to supervise their own responsible highway construction projects.

By transmitting the updated databases of the construction divisions distributed in this country, through the Internet system, to the headquarter of Highway Bureau for overall database update, this management information system can be maintained very easily.

We expect that this system will not be applied only in the daily management work, but also be used directly right in the meeting room to build up a paperless meeting environment in the near future.

Further works to be done, beyond this paper, include the integration of this management information system with the project financial control system and something else, so that the project progress can be monitored in phase with the project cost expenses.

\section{Acknowledgements}

The authors would like to thank all the colleagues who are responsible for the maintenance of the database of this management information to keep this system always in the right position. We also like to thank all the directors of the engineering departments, at headquarter, and the thirteen construction divisions, allocated around this country, for their supports to make this system available.

\section{REFERENCES}

[1] Microsoft Co., Visual FoxPro User's Reference Manual, $6^{\text {th }}$ Edition, 2000.

[2] Laudon, K. C. and Laudon, J. P., Management Information Systems, $6^{\text {th }}$ Edition, Prentice Hall, 2000. [3] Kuo, G. S. and Lin, J. P., "New Design Concepts for an Intelligent Internet", Communications of the ACM, Vol. 41, no.11, 1998.

[4] Cerveny, R. P., Garrity, E. J., and Sanders, G. L., "A Problem-Solving Perspective on Systems Development", Journal of Management Information Systems, Vol. 6, no. 4, 1990.

[5] Kendall, K. E. and Kendall, J. E., Systems Analysis and Design, $4^{\text {th }}$ Edition, Prentice Hall, 1998. [6] Hunton, J. E. and Beeler, J. D., "Effects of User Participation in Systems Development: A Longitudinal Field Study", MIS Quarterly, Vol. 21, no. $4,1997$.

[7] O'Leary, D. E., Koukka, D. and Plant, R., "Artificial Intelligence and Virtual Organizations", Communications of the ACM, Vol. 40, no.1, 1997.

[8] Halsall, F., Data Communications, Computer Networks and Open Systems, $4^{\text {th }}$ Edition, AddisonWesley, 1996. 